\title{
ELT Graduate Students' Challenges of Writing for Scholarly Publication: Discursive Perspectives
}

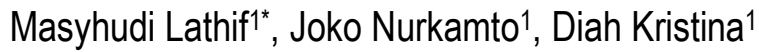 \\ 1 Universitas Sebelas Maret, Surakarta, Indonesia \\ ${ }^{*}$ Correspondence: masyhudilathif@gmail.com
}

\begin{abstract}
There has been an increasing demand for postgraduate students to publish their scholarly work as one of their graduation requirements. The present study attempted to explore the graduate students' challenges in writing for scholarly publication seen from the perspectives of discursive challenges. This qualitative research employed case study to disclose the participants' perceived constraints. The students participated in this study three final-year female students undertaking their master's degree in English Language Teaching (ELT) in a university in Central Java. Data were garnered from semi-structured interviews. The findings discovered the discursive challenges that the participants faced in writing for scholarly publication including accuracy, genre understanding, interference of $L 1$ to $L 2$ production, and lexical items. It is expected that this study provides new insights for EAP design for higher education context so that the program addresses the needs of the graduate students.
\end{abstract}

\section{ARTICLE HISTORY}

Published March 27 2021

Check for updates

\section{KEYWORDS}

Discursive Challenges,

Graduate Students, Writing for

Scholarly Publication

\section{ARTICLE LICENCE}

(C) 2021 Universitas Hasanuddin Under the license CC BY-SA

4.0

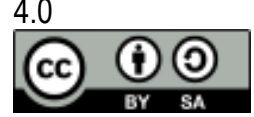

\section{Introduction}

The current trends of scholarly publications by academicians have been driven by the trends of global competition for academic excellence (Flowerdew, 2015). This implies that professors, lecturers, researchers and postgraduate students are required to write academically in English to disseminate their research by publishing their scholarly articles in reputable journals (Rahman, 2019). Such requirement in the academia is even strengthened with a well-known slogan of "publish or perish" (Habibie, 2016). It means that the existence of an academic in the world of academia truly depends on how the show their capacity to publish their scholarly work. In principle, such practice provides a means of being survived in the academic community and it leads to the recognition of being productive scholars as well.

As a result of the previously mentioned trends, research for publication has now been an indication of the pursuit of world-class universities as well as the mandatory requirement for quality assurance in higher education (Lei, 2019). He further suggests that such phenomenon has triggered more universities to pass the regulations of scholarly publication as either graduation requirement or expectation of postgraduate students, particularly doctoral students. In Malaysian context, for instance, there has been publication article requirement for postgraduate by research students in order to graduate from the university (Jeyaraj, 2018). Further, Cargill et al. (2018) report that Chinese PhD students are also demanded to publish their academic work in Thompson-Reuters' Science Citation Index (SCI) or now Web of Science (WoS) index or equivalent. For master's students, their publication might be in Chinese, yet publishing in English is highly encouraged to foster university reputation. Similarly, PhD students in Iranian universities are demanded to publish their academic papers in order to be able to defend their dissertations (Rezaei \& Syeiri, 2019).

As previously stated, the publication requirement for $\mathrm{PhD}$ students has been apparent in some countries. To date such requirement has also been passed to those studying in a master's degree level. Similar to those of doctoral students, master's degree students in some universities are also demanded to write for publication in order to obtain their degree. This phenomenon is, in fact, supported by Lei and Chuang (2009) who assert that such necessities are now becoming more apparent for graduate students currently enrolled in a master's level where students are mostly required to publish 
their research results in the form of articles published in scholarly journals upon graduating from their respective programs. In the national level, the obligation for masters students to write for academic publication as a part of their graduation requirement is accentuated by the Minister of Research and Higher Education regulation number 50/2018.

One notable challenge that scholarly writers often find in the process of writing their research articles is discursive challenges. Previous studies have outlined the term "discursive" in various ways which mostly cover grammar, lexis, genre, and so on (Corcoran, 2015; Fazel, 2019; Flowerdew, 2000; Habibie, 2016). However, attempt to draw a distinct categorization of discursive-related challenges to writing for scholarly publication has been made by Corcoran (2015). He outlines four elements related to discursive elements which most scholarly writers found to be problematic namely lexicogrammatical accuracy, clarity, genre, and linguistic transfer. In relation to the categorization, Corcoran then asserts that it is not intended to highlight an absolute aspect yet it is aimed at showing "heuristic device knowing full well that there is significant overlap between challenges and categories" ( $p .113)$.

As previously mentioned, the discursive constraints of writing for scholarly publication consists of four main elements, namely accuracy, genre, clarity, and L1 transfer to L2 production. Firstly, accuracy elements of writing are often referred to as surface level (Corcoran, 2015). This is primarily because most areas in which English as an Additional Language (EAL) scholarly writers often find problematic include grammar, active and passive voices, adjective use, hedging usage, and authorial voice display (Englander, 2006; Flowerdew, 2001; Swales, 1990). Next, clarity in academic writing is attributed to direct and focused style (Williams, 2007). Such concept is highly needed in writing for scholarly publication since clear writing is seen as a way to effectively publicize knowledge within academia (Gastel \& Day, 2016). Another important concept of discursive challenges of scholarly publication is genre understanding since such ability marks the writer's contribution into a scientific discourse community (Swales, 1990). Lastly, the intercultural transfer of L1 to L2 writing production might happen due to some differences in the form specific norms in writing academic articles in English (Englander, 2006).

Some studies have previously been conducted to examine the graduate students' challenges of writing for academic publication, particularly in doctoral education context. Grounded in narrative inquiry, Rezaei \& Seyri (2019) investigated nine Doctor of Science and Engineering students' scholarly publication experiences. One of the essential findings of their study is the participants' challenges in their publication process. The participants mostly reported that constraints in their publication process included political reasons, language-related problems, center-periphery priorities and the lack of academic writing instruction. In Chinese context, Mu (2020) conducted a research which examine the experience of multilingual Chinese writers in writing for scholarly publication in English. In regard to the challenges encountered, genre-related barriers, communication difficulties with the reviewer, unbalanced distribution of sources, and lack of training in EAP writing have been apparent constraints for the participants. However, little attention has been given to explore that issue in Indonesian context where master's degree students have been required to where there is also a demand to write for scholarly publication as a part of graduation requirements. Therefore, the present study was aimed at discovering ELT graduate students' discursive challenges in writing for scholarly publication.

\section{Method}

The current study investigated English Language Teaching (ELT) graduate students' challenges in writing for scholarly publication. More specifically, the challenges were scrutinized from the perspectives of discursive elements and non-discursive elements. Yin (2018) asserts that the primary reason of adopting case study as an approach in understanding such phenomena is that the case is "most likely to involve important contextual conditions pertinent to the case". Thus, this approach is adopted since the participants have experienced different types of challenges as well as they have discovered ways to overcome them reflected by their efforts in writing for scholarly publication in their master's education context.

In this study, data were obtained from three female participants who were doing their master's degree in English Language Teaching (ELT) in a state university in Central Java, Indonesia. They were final year students of that program. As a part of their graduation requirements, they were required to publish scholarly articles in reputable national or international journals. The scholarly articles published in such journals should have the same topic as their master's thesis. Before embarking on their scholarly publication journey, those two students have undertaken their academic writing course in their first semester of their study.

To recruit the participants, the researcher sent an invitation to reach potential participants through the researcher's personal links. The researcher selected the one to be contacted by considering that the participants were the final-year students of master's program in ELT and should have at least one scholarly article published in a reputable journal. After 
the participants have agreed to be interviewed, the researcher then negotiated the time allocation for conducting the interview. The interview schedule was later proposed in accordance with the participants' available time.

The data of the present study were collected using semi-structured interview. Semi-structured interview was primarily adopted as the method of data gathering due to its benefit "to let the interviewee develop ideas and speak more widely on the issues raised by the researcher" (Cohen et al., 2018: 176). The interview session was conducted for approximately 50-75 minutes. In so doing, the researcher designed an interview protocol which comprised of the interview questions and necessary instructions for both interviewer and interviewees. The interview protocol was developed in accordance with Creswell's framework (2012). The researcher prepared the interview questions in L1 (Bahasa Indonesia) so that this could ease the participants' comprehension to the given questions. To respond to the interview questions, the participants were required to reflect on their process of revising their draft of scholarly writing as well as their strategies in doing so.

In conducting the interview, the researcher recorded the participants' responses so that they could be analyzed later. Once the interview was done, the next step was doing analysis, comprising of such three stages as transcription, coding, and analysis. Transcription was considered pivotal in this study to highlight some major findings. Selective coding was then utilized for analysis to emphasize the relationship between the participants' experiences and the theoretical bases underpinning academic writing as presented previously (Clarke, 2005). The transcripts for discussion revealed the participants' voices of their experiences and reflections. Excerpts of interview transcripts in the findings were the main results obtained from the interview.

\section{Findings and Discussion}

This section elaborates the analysis of the challenges encountered by the participants in writing for scholarly publication. The themes of the challenges were developed based on Corcoran's (2015) categorization of discursive challenges of writing for scholarly publication. The main findings of this study revealed the participants' perceived difficulties in writing for scholarly publication as seen from the linguistic elements. In principle, most participants faced difficulties in terms of using grammar, understanding the genre of scholarly work, and the influence of the participants' first language (L1). However, the participants reported no barriers in stating their research goals in their manuscript. The detailed explanation of those challenges is elaborated as follows.

\subsection{Accuracy: Using Grammar in their Manuscripts}

In relation to accuracy, all the participants interviewed expressed their ideas that grammar was not a big issue for them. Since all of them have undertaken their bachelor's degree in English Language Teaching, the have been learning structure and grammar courses for several years. Additionally, their master's curriculum structure has provided one coursework for mastering advanced grammar. However, two participants of this study, Alya and Hana, reported that they found it problematic with the complex sentence formation as well as the time conception as represented in English tenses. Alya's problem was related to the construction of complex sentences and the present and past usage in certain parts of her draft. Similarly, Hana found it problematic in differentiating which part should be expressed by using present tense and past simple. Supporting their perceived constraints in this area, Alya's journal reviewers commented that she needed to pay more attention to the accuracy of the use of that/ which in her draft. Similarly, the reviewers of Hana's draft suggested that she should be more consistent in using both present and simple past. The participants' voices regarding the challenges of using grammar in their draft are shown in the following excerpts of interview.

I have some troubles with grammar in the tenses and complex sentences. This is especially on selecting simple past and present tense. I am still a bit confused in determining the use of both in certain parts of my article. Besides, I also find it difficult to use complex sentences, especially in using the which / that clause. My reviewers pointed out that I should be more careful in those areas. (Alya)

We are Indonesians, so I always find it difficult in grammar. Even though I have used Grammarly, I do not think that my grammar is appropriate for scholarly publication. What becomes my biggest challenge is that I could not think automatically the instance of using simple past to show past activities and the instance of using present tense to show a common occurrence. (Hana).

The participants' constraints in grammar resonate with the problems encountered by participants in Fazel's (2019) study. Even though one of the participants in his study is a native speaker, the participant pointed out that her journal reviewer showed three grammatical errors in her draft. This further proves that even a native speaker also finds it problematic with the use of grammar in scholarly publication work. In a similar vein, McDowell \& Liardét, (2019) also 
discover that some senior and junior Japanese scientists' papers were rejected because of the language errors they produced.

\subsection{Genre : Understanding the Genre of Scholarly Writing}

Another constraint reported by the participants during the interview was related to understanding the genre of scholarly writing. The genre of scholarly work is closely linked to its rhetorical elements. Understanding such concepts were proven to be problematic for the participants of this study, especially at the beginning of their master's degree. This was mostly because the participants had no idea of what to include of each section of the paper. In addition, they also had no clear understanding of what to write in introduction, method, results and discussion, and conclusion. However, as the participants undertook their academic writing course, they then recognized the rhetorical elements of an academic paper for publication and the aspects that they should include in each section of the paper. The following interview excerpt shows the participants' constraints in understanding the rhetorical element as the realization of genre of scholarly writing.

I think it is not a big issue now. It used to be a problematic issue back then. Before I did my academic writing course, I just wrote carelessly because I didn't know what elements should be in each section. (Amira)

When I first entered this master program, I had great difficulty understanding the rules of writing scientific papers. This is because I have never studied this material in my undergraduate program. I participated in Prof. X's workshops several times and he discussed clearly the genre of writing scientific papers for publication. So, I already have an idea of what I should write in the scientific article. (Hana)

As being reported in other studies, the problem of understanding the genre of academic writing for publication has been a common issue. In a study conducted by (Jeyaraj, 2018), one participant underwent the feeling of uncertainty and confusion in structuring her literature review as she was not really sure whether she has included sufficient theories there. Similarly, one doctoral student in Fazel's (2019) reported his difficulties in understanding the genre differences between the empirical and conceptual journal articles, which often made him question some of his basic understanding of research.

\subsection{Interference of L1: The Influence of Bahasa Indonesia}

The participants in this study generally reported that their $L 1$ style of writing influenced their $L 2$ practices. More specifically, this instance was closely related to how they express their ideas in English. In general, all participants reported that the way they found it problematic with writing English naturally in academic context. Some participants recounted that they often thought in L1 first before later translating those sentences into English. This case was reported by Amira who admitted that she found some of her writing in English was not that natural compared to those produced by experienced scholarly writers. In a similar vein, Alya voiced that her major constraints in terms of L1 transfer in L2 production of writing was related to her using direct translation method in expressing certain words. She then admitted that her strategy resulted in unnatural terminologies in English. In addition, Hana started her writing by brainstorming and jotting ideas down in L1 which further influenced the way she expressed her sentences in $L 2$.

Indonesian is our mother tongue. In writing my draft, I still produced English utterances which were from the translated Indonesian version. When I read the text, the results were less natural. The results were less smooth than the written versions of those published in international journals. (Amira).

I think the influence of Bahasa Indonesia is apparent in my scientific articles. The thing that often makes it difficult for me to write scientific papers is expressing vocabulary in English. Also, I have difficulties in expressing ideas in English naturally. In writing, I often produce English writing with the "Indonesian taste". (Alya)

I understand how to write in English appropriately but my mother tongue affects me very much. I usually write my ideas in Indonesian. I then translate my ideas into English. That's why my English is a bit Bahasa Indonesia version sometimes. (Hana).

The case of $L 1$ transfer to the $L 2$ writing production was also apparent in a study conducted by (Corcoran, 2015). He reported that participants in his study admitted that they found some constraints in transmitting their ideas from Spanish (L1) to English (L2). The fact was that most participant in Corcoran's study wrote their draft from the Spanish version to be later translated to English. Such practice was actually done by the participants in this current research where some of them started with the Bahasa Indonesia version in dealing with their draft. Supporting this, the practice of inter-linguistic working from L1 to L2 in transferring theses into publishable articles has been documented in another research as well (e.g. Kwan, 2010).

\subsection{Lexical Items: Using Academic Vocabulary}


The analysis of the interview results generated one prominent challenge encountered by the participants in writing their drafts for scholarly publication. The constraint was using academic vocabulary which was perceived by all participants in this study. In principle, the participants voiced their barriers in using appropriate academic vocabulary to express their thought. As all participants are students of Master's degree in ELT, all of them perceived that they have mastered general vocabulary. However, when it came to academic vocabulary, they pointed out the difficulties in navigating certain words or terminologies which were suitable for scholarly work. Further, Amira voiced the reason why she found it challenging in navigating appropriate academic vocabulary which was due to the different nature of academic vocabulary and general vocabulary for everyday uses. Hana then added that "academic vocabulary is advanced so that is why it should be acquired through reading scholarly work extensively". Hana's statement then reinforced the challenging nature of academic vocabulary as it was specifically used for publication purposes.

These findings are consonant with the previous studies conducted by Corcoran (2015) and Habibie (2015). Both studies discovered that EAL writers often find it challenging in using both academic and disciplinary vocabulary in their draft of scholarly publication. The doctoral student as one participant in Corcoran's study recounted her lack of confidence in using academic vocabulary in her writing because of her low English ability. This was further recounted by the EAP instructor in that study who voiced his concern towards the problems of academic vocabulary use as shown by the doctoral students in Corcoran's research. Similarly, three doctoral students in Habibie's (2015) study expressed their barriers in deciding what vocabulary to use in their draft, which he later referred to as discipline-specific vocabulary (p. 76).

\section{Conclusion}

This study has examined ELT graduate students' challenges of writing for publication. Those constraints were analyzed by using the notion of discursive challenges as proposed by Corcoran (2015). Those discursive challenges could be then thematized into four main themes namely accuracy, genre, $L 1$ transfer to $L 2$ writing production, and lexical items. One main element of discursive challenge, clarity of research goals, was not apparent in this present research. The findings of the analysis to the participants' interview then pointed out to each specific constraint they faced in writing for scholarly publication. In terms of the accuracy, the participants recounted their challenges in using complex sentences and mastering the concept of time as realized in tenses. With regard to the understanding the rhetorical elements as the genre of scientific articles, most participants initially found it problematic in mastering it. However, as they undertook academic writing class and attended academic writing workshop, such problem was no longer an issue. Then, L1 transfer to the L2 writing production was another challenge for them as seen from their perception of their English writing which was sometimes unnatural. Finally, the participants also mentioned that academic vocabulary as one of the barriers in wiring their scholarly writing draft due to its complexity.

As stated earlier in the previous section of this paper, the present study is a small-scale case study. The data of this study were obtained from three graduate students of ELT who undertake their master's degree in a public university in Central Java. Therefore, this study might not provide generalizable findings to be applied in different postgraduate education contexts. Richer data then could be yielded by recruiting more participants from different graduate programs across Indonesian universities or teacher training institutes. To deal with those shortcomings, more participants from different universities could be recruited. Additionally, graduate students undertaking their program in master's courses other than ELT could also be taken into consideration as they make the data richer. With regard to the data collection technique, more instruments could be then utilized such as questionnaire and guided written reflection to offer more detailed data.

This study has shed light on the discursive constraints of writing for scholarly publication as perceived by master's students in English Language Teaching. The findings of the present study could inform the policy makers in the postgraduate education context. More specifically, those working in the area of English for Academic Purposes course design. The design of EAP course for master's students, as realized by the provision of academic writing course, should be linked to their barriers in writing for scholarly publication so that the materials could be developed based on the empirical data. In addition, such information will be of beneficial to the supervisors or faculty members who are in charge of monitoring students' journey of scholarly publication. It is then expected that the training of EAP and mentoring could cover the graduate students' difficulties in writing for publication which later could enhance the quality of the program they received. 


\section{Acknowledgments}

I would like to express my gratitude to my thesis supervisors, Prof. Dr. Joko Nurkamto and Prof. Diah Kristina, Ph.D., who guided me throughout this project. I would also like to thank all participants who were willing to take part in this research.

\section{References}

Cargill, M., Gao, X., Wang, X., \& O'Connor, P. (2018). Preparing Chinese graduate students of science facing an international publication requirement for graduation: Adapting an intensive workshop approach for earlycandidature use. English for Specific Purposes, 52, 13-26. https://doi.org/10.1016/j.esp.2018.05.002

Clarke, A. E. (2005). Situational analysis. https://www.doi.org/10.4135/9781412985833

Cohen, L., Manion, L., \& Morrison, K. (2017). Research methods in education (8th ed.). https://doi.org/10.4324/9781315456539.

Corcoran, J. N. (2015). English as the international language of science: A case study of Mexican scientists' writing for publication (PhD Thesis). In ProQuest Dissertations and Theses. https://tspace.library.utoronto.ca/handle/1807/70842.

Creswell, J. W. (2012). Qualitative inquiry \& research design: Choosing among five approaches (4th ed.). Thousand Oaks, CA: Sage.

Cohen, L., Manion, L., \& Morrison, K. (2018). Research methods in education (8th ed.). https://doi.org/10.4324/9781315456539

Englander, K. (2006). Non-native English-speaking scientists' successful revision for English-language publication: A discourse analytic and social constructivist study (PhD thesis). Indiana University of Pennsylvania, Indiana, PA.

Fazel, I. (2019). Writing for publication as a native speaker: The experiences of two Anglophone novice scholars. In P. Habibie \& K. Hyland (Eds.), Novice writers and scholarly publication: Authors, mentors, gatekeepers (pp. 79-96). https://doi.org/10.1007/978-3-319-95333-55

Flowerdew, J. (2000). Discourse community, legitimate peripheral participation, and the nonnative-English-speaking $\begin{array}{llll}\text { scholar. TESOL } & \text { Quarterly, } & \text { 34(1), }\end{array}$ http://www.scopus.com/inward/record.url?scp=0038216182\&partnerlD=8YFLogxK

Flowerdew, J. (2001). Attitudes of journal editors to nonnative speaker contributions. TESOL Quarterly, 35. https://doi.org/10.2307/3587862

Flowerdew, J. (2015). Some thoughts on English for Research Publication Purposes (ERPP) and related issues. Language Teaching, 48(2), 250-262. https://doi.org/10.1017/S0261444812000523

Gastel, B., \& Day, R. A. (2016). How to write and publish a scientific paper. Cambridge: Cambridge University Press.

Habibie, P. (2015). An Investigation into writing for scholarly publication by novice scholars: Practices of Canadian anglophone doctoral students (PhD thesis). Electronic Thesis and Dissertation Repository. https://ir.lib.uwo.ca/etd/3281

Habibie, P. (2016). Writing for scholarly publication in Canadian higher education context: A case study. In C. M. Badenhorst \& C. Guerin (Eds.), Research literacies and writing pedagogies for masters and doctoral writers. Leiden: Brill Publishing.

Rahman, F. (2019). Meretas Jalan Publikasi Jurnal Internasional bagi PTN-PTS di Kota Watampone. Jurnal IImu Budaya, 7(1), 146-151.

Jeyaraj, J. J. (2018). It's a jungle out there: Challenges in postgraduate research writing. GEMA Online Journal of Language Studies, 18(1), 22-37. https://doi.org/10.17576/gema-2018-1801-02

Kwan, B. S. C. (2010). An investigation of instruction in research publishing offered in doctoral programs: The Hong Kong case. Higher Education, 59(1), 55-68. https://doi.org/10.1007/s10734-009-9233-x 
Lei, J. (2019). Publishing during doctoral Candidature from an activity theory Perspective: The case of four Chinese nursing doctoral students. TESOL Quarterly, 0(0), 1-30. https://doi.org/10.1002/tesq.501

Lei, S., \& Chuang, N. (2009). Research collaboration and publication during graduate studies: Evaluating benefits and costs from students' perspectives. College Student Journal, 43, 1163-1168.

McDowell, L., \& Liardét, C. L. (2019). Japanese materials scientists' experiences with English for research publication purposes. Journal of English for Academic Purposes, 37, 141-153. https://doi.org/10.1016/j.jeap.2018.11.011

$\mathrm{Mu}, \mathrm{C}$. (2020). Understanding Chinese multilingual scholars' sxperiences of writing and publishing in English. https://doi.org/10.1007/978-3-030-33938-8

Rezaei, S., \& Seyri, H. (2019). Iranian doctoral students' perceptions of publication in English: Motives, hurdles, and strategies. Journal of Applied Research in Higher Education, 11(4), 941-954. https://doi.org/10.1108/JARHE-02$\underline{2019-0040}$

Swales, J. (1990). Genre analysis: English in academic and research settings. Cambridge: Cambridge University Press. Williams, J. M. (2007). Style: Lessons in Clarity and Grace. Pearson Longman.

Yin, R. K. (2018). Case Study Research and Applications: Design and Methods (6th Ed, Issue 6e). Thousand Oak: Sage. 